\title{
O processo de adaptação familiar à hospitalização infantil em Unidade de Terapia Intensiva*
}

\author{
The family's adaptation process to their child's hospitalization in an Intensive Care Unit \\ El proceso de adaptación familiar a la hospitalización infantil en una Unidad de Cuidados Intensivos
}

Como citar este artigo:

Bazzan JS, Milbrath VM, Gabatz RIB, Cordeiro FR, Freitag VL, Schwartz E. The family's adaptation process to their child's hospitalization in an Intensive Care Unit. Rev Esc Enferm USP. 2020;54:e03614. doi: https://doi.org/10.1590/S1980-220X2018056203614

\section{Jéssica Stragliotto Bazzan' \\ Viviane Marten Milbrath ${ }^{2}$ \\ Ruth Irmgard Bärtschi Gabatz ${ }^{2}$ \\ Franciele Roberta Cordeiro ${ }^{2}$ \\ Vera Lucia Freitag 3 \\ Eda Schwartz ${ }^{2}$}

* Extraído da dissertação: "Processo de adaptação de familiares de crianças internadas em Unidade de Terapia Intensiva Pediátrica”, Universidade Federal de Pelotas, 2018.

${ }^{1}$ Universidade Federal de Pelotas, Programa de Pós-Graduação em Enfermagem, Pelotas, RS, Brasil.

${ }^{2}$ Universidade Federal de Pelotas, Faculdade de Enfermagem, Pelotas, RS, Brasil.

${ }^{3}$ Universidade de Cruz Alta,

Porto Alegre, RS, Brasil.

\begin{abstract}
Objective: To learn about the adaptation process of family members when experiencing their child's hospitalization in an Intensive Care Unit. Method: A qualitative, descriptive and exploratory study conducted at the Pediatrics Unit with family members of children from the Pediatric Intensive Care Unit. The thematic analysis technique was used. Results: Thirteen (13) family members, 12 mothers and one father participated. The following categories emerged from the results: Family impact on children's hospitalization in a Pediatric Intensive Care Unit and Mechanisms for adapting family members to hospitalization in a Pediatric Intensive Care Unit. Conclusion: The mechanisms adopted by the family in the process of adapting the child to admission to the Pediatric Intensive Care Unit were: positive thinking, understanding the treatment and the operation of the unit. Health professionals can offer strategies to the family in order to make hospitalization less traumatic, making it possible to share experiences and expand the knowledge of those involved.
\end{abstract}

\section{DESCRIPTORS}

Child, Hospitalized; Family; Caregivers; Intensive Care Units, Pediatric; Pediatric Nursing; Professional-Family Relations. 


\section{INTRODUÇÃO}

A família é o primeiro espaço de formação psíquica, moral, social e espiritual da criança ${ }^{(1)}$. O processo de adoecimento da criança é uma situação que modifica e impacta na dinâmica familiar, sendo permeado por dúvidas e incertezas, o que acarreta sofrimento psíquico para a família e a criança doente $^{(2)}$. Se a hospitalização, por si só, é um evento atribulador, gerador de estresse e de insegurança, devido à condição de vulnerabilidade da saúde da criança, o enfrentamento desta situação é ainda mais difícil.

Ao receberem a notícia da necessidade de internação da criança em uma Unidade de Terapia Intensiva Pediátrica (UTIP) as famílias desesperam-se, sentem medo e insegurança, iniciando um estado de vigilância contínua, motivado por preocupação, sobretudo quando vivenciam a internação pela primeira vez. Nesse momento, verifica-se que as famílias iniciam o processo de adaptação para o enfrentamento da situação(3).

Quando a hospitalização ocorre em UTIP a situação reveste-se de nuances de maiores proporções. Para os familiares da criança internada, a doença é um evento súbito que a família não espera. Assim, quando elas experienciam o fenômeno do adoecer, tornam-se vulneráveis devido ao impacto e às incertezas geradas pela doença ${ }^{(4)} \mathrm{e}$ internação. Embora possa ser explicado em termos técnicos, é difícil para os familiares entenderem e aceitarem emocionalmente os fatos.

O ambiente da UTIP pode constituir-se como uma ameaça à família, pois ela se encontra em um local desconhecido, podendo ocorrer ruptura na interdependência afetiva entre seus membros. A interdependência pode ser compreendida como as relações em que ocorre troca de amor, respeito e valores entre os indivíduos, favorecendo o sentimento de segurança em um determinado contexto ${ }^{(3)}$. O impacto frente à hospitalização infantil necessita ser trabalhado com os familiares, visando minimizar o estresse e o sofrimento, proporcionando um ambiente mais confortável para a adaptação em relação à situação a ser vivenciada ${ }^{(5)}$.

Diante da internação as famílias podem mostrar-se adaptadas à situação, por meio de respostas adaptativas, ou seja, aquelas capazes de promover integralidade da pessoa, em termos de sobrevivência, crescimento, reprodução e domínio. A adaptação também se dá pelas respostas adaptativas ineficazes, consideradas aquelas que não promovem a integralidade e nem contribuem para os objetivos da adaptação, e que podem ameaçar a sobrevivência da pessoa, o crescimento, a reprodução e o domínio, mesmo nessas condições, ainda é uma resposta adaptativa. Assim, para avaliar o processo é preciso olhar para o comportamento individual, de acordo com os objetivos gerais da adaptação ${ }^{(3)}$. A forma como o processo acontece desencadeará mecanismos de adaptação que implicarão no modo de enfrentamento ao processo de hospitalização.

Com base no exposto, o ponto de partida desta pesquisa foi a elaboração da questão norteadora: Como ocorre o processo de adaptação de familiares ao vivenciar a internação da criança em uma Unidade de Terapia Intensiva? A fim de responder tal questão, este estudo teve por objetivo conhecer o processo de adaptação de familiares que vivenciam a internação da criança em uma Unidade de Terapia Intensiva.

\section{MÉTODO}

\section{TIPO DE ESTUdo}

Estudo qualitativo, descritivo e exploratório.

\section{CenÁrio}

O estudo foi realizado em um hospital geral de grande porte localizado na Região Sul do Rio Grande do Sul. O hospital tem atendimento geral misto: público e privado, deste modo, a UTIP conta com oito leitos destinados para atendimento do Sistema Único de Saúde e dois leitos para Planos de saúde privados, a coleta se deu durante os meses de junho e julho de 2017.

\section{PopulaÇão}

Os critérios de inclusão dos participantes foram familiares cuidadores de crianças que acompanharam a internação na UTIP e cujas crianças tiveram alta no período da coleta de dados, independente do número de internações que a criança já tivesse em seu histórico. Os critérios de exclusão foram familiares de crianças que evoluíram para óbito; familiares de crianças em cuidados paliativos e familiares de menores de 18 anos de idade.

\section{Coleta de dados}

Como técnica de produção de dados optou-se pela entrevista semiestruturada, pois os dados são obtidos diretamente das falas, pelo relato das experiências, sentimentos e percepções em torno de um assunto específico. O convite para participação foi realizado cara a cara pela entrevistadora, enfermeira e mestranda com experiência em pesquisas qualitativa e que não conhecia previamente nenhum dos participantes. Todos os convidados aceitaram participar, não havendo recusa em nenhum momento durante e após a entrevista. No momento do convite foi apresentado o Termo de Consentimento Livre e Esclarecido em duas vias, lido, sanado dúvidas, assinado pelo participante e entregue uma via ao mesmo e a outra permaneceu com a pesquisadora. A escolha dos participantes foi intencional, a cada admissão na Unidade Pediátrica após a alta da UTIP.

As entrevistas foram realizadas por meio de um questionário semiestruturado, com questões fechadas traçando o perfil dos entrevistados e uma questão aberta, para a análise deste artigo utilizamos a seguinte questão: Fale sobre como foi vivenciar a internação do seu filho(a) na UTIP e como você fez para adaptar-se.

Cada entrevista foi realizada no quarto, na unidade de Pediatria, conforme escolha dos participantes, estava presente no local o familiar a ser entrevistado, a criança e a pesquisadora, teve duração média de 30 minutos, gravadas individualmente em áudio com aparelho MP4. Participaram do estudo 13 familiares de crianças que receberam alta da 
UTIP, sendo 12 mães e um pai. O número de entrevistas foi interrompido quando houve suficiência de significados ${ }^{(6)}$.

Os entrevistados foram identificados como F1, F2, respectivamente, com a letra "F" corresponde a "Família", seguidos por número sequencial, conforme a ordem das entrevistas.

\section{ANÁLISE E TRATAMENTO DOS DADOS}

Para a interpretação dos dados foi utilizada a análise temática de Braun e Clarke que se constitui de seis fases: $1^{\circ}$ fase: familiarizando com seus dados, $2^{\circ}$ fase: gerando códigos iniciais, $3^{\circ}$ fase: buscando por temas, $4^{\circ}$ fase: revisando os temas, $5^{\circ}$ fase: definindo e nomeando temas, $6^{\circ}$ fase: produzindo o relatório ${ }^{(6)}$. Os resultados foram discutidos sob a luz da Teoria da Adaptação, da Enfermeira Callista Roy ${ }^{(3)}$.

De acordo com o modelo de Callista Roy, a pessoa é um sistema adaptável, em que a entrada, por meio de estímulos, sejam eles focais, contextuais ou residuais, ativa mecanismos reguladores e cognitivos com objetivos de promover a adaptação; já as saídas das pessoas, são as suas respostas, isto é, o seu comportamento, que derivará das respostas adaptativas ou das adaptativas ineficazes. Os estímulos causam comportamentos diferenciados nos indivíduos, pois estão relacionados a fatores intrínsecos de enfrentamento. Assim, a meta da enfermagem é promover a adaptação da pessoa, grupo ou comunidade a partir dos modos adaptativos e contribuir para a promoção da saúde dos indivíduos ${ }^{(3)}$.

\section{AspeCtos ÉTICOS}

A pesquisa foi desenvolvida respeitando os preceitos éticos da Resolução 466/12, do Conselho Nacional de Saúde ${ }^{(7)}$, que trata sobre a pesquisas envolvendo seres humanos. $\mathrm{O}$ projeto foi aprovado pelo Comitê de Ética da Faculdade de Enfermagem da Universidade Federal de Pelotas, sob o Parecer n. 2.197.011/17.

\section{RESULTADOS}

Participaram do estudo 13 familiares de crianças que receberam alta da UTIP, sendo destes 12 mães e um pai, com idades entre 18 anos e 39 anos. Quanto ao estado civil, cinco participantes eram casados e oito solteiros. Quatro participantes vivenciavam o processo de internação pela primeira vez e nove vivenciavam a reinternação. Quatro participantes declararam-se católicos, dois ateus, um evangélico e cinco referiram não ter religião, mas disseram acreditar em Deus. Após a análise de dados emergiram as seguintes categorias: "O impacto da familia frente à internação infantil em UTIP" " "Mecanismos de adaptação de familiares à internação em uma UTIP”.

\section{O IMPACTO DA FAMÍLIA FRENTE À INTERNAÇÃO INFANTIL EM UTIP}

A vivência da família frente à internação de um filho na UTIP causa impacto, que em um primeiro momento gera sentimentos de angústia pela criança não acordar, devido a sedação, além da presença de diferentes dispositivos, até então desconhecidos pelos familiares. Neste sentido, a família sofre por não conseguir ajudar e teme pela vida da criança. A primeira vez que eu vi foi um impacto, não foi fácil, ai tu quer que aquela pessoa acorde e ela não acorda (F1).
Bem mal, porque é ruim de ver, sedada e com tudo aquilo ligado nela [dispositivos], tu fala com ela, eu sabia que ela estava sedada, mas ela não reagia, é complicado! (F3).

Horrivel, muito sofrido (...) eu tive que ser bem forte (F6).

É horrível, a sensação de tu vê, lá dentro, aquelas crianças ligadas a aqueles aparelhos (F7).

Não foi muito fácil, a gente se desespera de ver um filho naquela situação, eu ficava bem para baixo, bem nervosa, mas eu tinha que ter força porque ele só dependia de mim lá dentro (F9).

Nesse contexto, a família percebe sua vulnerabilidade como ser humano, um ser instável que a qualquer momento poderá necessitar de apoio para enfrentar a situação em que se encontra.

Ai difícil, primeiro porque assim, olha, é aonde tu vê [percebe] como tu é sensivel, vulnerável, dependendo de todo mundo, mas tu não pode interagir muito com ele, mesmo tu sabendo que ele está sedado (F5).

Imagina, eu jamais pensei em um dia ter que viver tudo isso aqui, estamos sem chão, na espera de dias melhores (F12).

A experiência de hospitalização na UTIP é descrita pelos familiares como o pior momento de suas vidas, conforme demonstram os enxertos abaixo.

A pior coisa que eu já passei, para uma mãe ver um filho assim, é muito difícil! [Choro] (F2).

A pior coisa do mundo, algo que parece que nunca vai passar, um sofrimento constante (F13).

Por outro lado, o processo de hospitalização traz sentimentos positivos às famílias, os quais se relacionam com a segurança oferecida pelo ambiente, os materiais e a equipe hospitalar.

Me senti muito segura com a situação que ele estava, era o único lugar que tinha, ali dentro [UTI] ele estava monitorado, [com] médicos 24 h ali, e então eu fiquei tranquila, mesmo que a gente fique angustiada por não ter uma melhora súbita, porque a gente quer que ele chegue e já melhore, mas mesmo assim ele melhorou muito rápido. Achei que ali ele teve uma melhora a olhos vistos, tu olhava e via a melhora dele (F5).

Quando ele foi para UTI, que a gente viu que ele começou a melhorar, nós nos sentimos mais seguros (F8).

Eu achava muito mais seguro ele estar lá [na UTI], eu me sentia mais segura, mais protegida com ele ali (...) do que [com] ele fora $\operatorname{dali}(\mathrm{F} 10)$.

Assim, pode-se observar que o familiar inicia um processo de adaptação já no momento da internação, visto que recebe estímulos focais e contextuais ao se impactarem com o ambiente da UTIP, com todos os dispositivos ligados à criança, com a gravidade do estado clínico, gerando sentimentos de angústia e sofrimento psíquico. Entretanto, quando os familiares compreendem o que está acontecendo e como será o tratamento do seu filho, passam a manifestar um comportamento adaptativo, sentindo-se seguros por seu filho se encontrar em um local com tantos recursos tecnológicos. 


\section{MeCANISMOS DE ADAPTAÇÃO DE FAMILIARES À} INTERNAÇÃO EM UMA UTIP

Após os primeiros impactos da hospitalização do filho, os familiares demonstram comportamentos que denotam a adaptação frente ao novo ambiente. Tal reação faz com que consigam permanecer mais tempo com a criança, mesmo diante de sentimentos como a angústia e o medo.

Primeira vez foi mais, eu me assustei porque [ela] era muito pequenininha, foi bem difícil. Eu entrei e não conseguia nem fica lá dentro para ver ela, depois de dois dias eu consegui entrar e ficar mais tempo, ai depois eu já estava me acostumando (F3).

É tudo muito difícil, mas os dias vão passando e tu vai entendendo como tudo funciona, e tudo vai melhorando, tu se sente mais confortável com o ambiente com a situação toda por mais angustiante que seja (F13).

Os familiares relatam que o impacto inicial vai sendo administrado e alterado, sendo que após algum tempo 'se acostumam'e transformam o olhar impactante sobre os dispositivos tecnológicos, conforme demonstram os excertos abaixo.

É horrivel, é uma essa sensação que parece que vai acontecer uma coisa muito ruim, é essa sensação que a gente tem quando tu vês, depois passa, depois tu acostuma, é só o primeiro impacto, mas isso passa. É uma coisa que toda vez tu vais chegar e olhar, é só primeiro [momento], depois passa, (...) depois tu já vês normal, como se fosse uma roupa [monitoramento cardíaco], é assim que a gente vê(F5).

A gente tem que vivenciar um dia de cada vez né. Os primeiros dias foram horríveis, depois tu já acostumas ali dentro (F7).

Eu tive que me adaptar (...) não tive outra escolha, tive que encarar e ser forte (F6).

Por outro lado, F12 apresenta outras estratégias que auxiliam no enfrentamento da situação em busca da adaptação:

Vai aprendendo, se a gente não pensa positivo sempre, se a gente não pensa, se eu não pensasse que meu filho vai melhorar, se a minha familia não manda energia positiva para mim, meus amigos, eles sabem também, a gente perde as forças, eu estou aqui sozinha (F12).

Com o passar dos dias, ao observar a dinâmica da unidade e conhecer a experiência de outras famílias, os familiares confortam-se e passam a se adaptar, se acostumando com as situações experienciadas.

Achei muito, muito, muito tenso, mas depois eu fui me acostumando, me acostumando e ao longo do tempo a gente vai se acostumando (...) com o clima aqui, que vai chegar crianças, que tem criança que está ruinzinha no salão [UTIP] que ele estava mesmo. Na parte de lá, tinha uma guriazinha que estava bem ruinzinha, toda hora fazendo procedimento, estava bem ruim (...) vejo que meu filho não está tão ruim. Não vou dizer que me acostumei com aquilo, mas já estava sabendo lidar comigo (F4).

\section{DISCUSSÃO}

Durante o período vivenciado na UTIP, relacionando o impacto da internação com o nível de adaptação, os familiares são confrontados a partir de estímulos focais, contextuais ou residuais.
O estímulo focal, interno ou externo, é o que mais imediatamente confronta o familiar, o acontecimento que atrai a atenção da pessoa, neste caso a visão do filho em um leito de UTIP, gravemente acometido por uma enfermidade, ligado a dispositivos e com iminência de morte. Já o estímulo contextual, nesse caso, está relacionado a todos os estímulos presentes na situação, por exemplo, fatores ambientais que influenciam diretamente como o familiar irá lidar com o estímulo focal. O termo adaptável significa que o sistema humano tem a capacidade de se ajustar efetivamente às mudanças no meio ambiente e, por sua vez, afeta o ambiente $^{(3)}$.

A partir disso, o familiar é confrontado com diversos estímulos dentro do ambiente hospitalar que geram impactos e, por consequência, elabora uma adaptação, com seu ponto de mudança voltado para a capacidade de entendimento do que está acontecendo e a absorção do que está por vir, em meio ao tratamento de seu filho ${ }^{(3)}$. Perante o momento vivido pelos familiares, quando entram em contato com as transformações derivadas do tratamento e com a possibilidade de morte, muitos sentimentos podem emergir, por exemplo, medo, insegurança, angustia e solidão, desorganizando seus membros ${ }^{(8)}$. Assim, ao sofrer um estimulo, os familiares projetam suas expectativas de futuro para um processo adaptativo inerente ao período de hospitalização.

A família, em seu processo adaptativo, recebe como entrada um estímulo focal, que a confronta com o momento da internação na UTIP, por meio da percepção da gravidade do estado de seu filho, ligado a aparelhos tecnológicos e dispositivos invasivos. Assim, ela entra em sofrimento momentâneo, desestruturando tudo o que idealizava sobre uma infância saudável e plena.

Ser familiar de um bebê ou de uma criança que tenha sido colocada em tratamento intensivo é uma experiência muito difícil ${ }^{(9)}$, critica, delicada e carrega um grande estresse psicológico e uma disparidade emocional, que tem efeitos cumulativos com longos períodos de internação devido às peculiaridades do ambiente hospitalar, levando a sentimentos como tristeza, ansiedade ${ }^{(10)}$, devido aos familiares necessitarem entender, em um curto prazo de tempo, o diagnóstico, a cirurgia e o tratamento imposto, o que os leva a compreender o processo saúde doença e aprender a lidar emocionalmente com as mudanças que ocorrem ${ }^{(11)}$.

Reafirma-se em estudo internacional que os membros de uma família formam um sistema, eles geralmente vivenciam sintomas psicológicos que podem consequentemente resultar em transtornos de estresse, depressão e ansiedade advindos do processo de hospitalização, os quais podem persistir após a alta, já dentro das enfermarias e até mesmo após alta hospitalar ${ }^{(12)}$.

Estudo refere que a família sofre com a ausência do membro doente e começa a aprender a viver com a interrupção momentânea na rotina familiar. Assim, a família, especialmente a mãe, passa a dedicar seus dias ao cuidado da criança enferma, alterando seu cotidiano perante a aflição que permeia a situação, além do medo constante do falecimento da criança. Esse evento estressor também correlaciona-se ao fato da família não estar preparada para todas as mudanças advindas a partir da internação repentina e de todo seu curso hospitalar ${ }^{(13)}$. 
O exercício do cuidar estabelece que quem cuida tenha um rompimento do modo de vida que antes era levado, anterior a doença. Assim, para acompanhar um paciente internado é indispensável uma revogação da sua individualidade, pois o cuidador familiar abre mão das atividades de lazer e abdica do trabalho para estar a serviço do doente ${ }^{(8)}$, atrelado as angustias e medos provenientes do momento vivenciado.

Perante as mudanças, o estímulo focal exemplifica-se também quando a família entra na UTIP pela primeira vez. Nesse momento os familiares lidam com diversas sensações, dentre as quais, a visão de uma criança não saudável, cercada de aparelhos. Tal situação é definida pelos familiares como dolorosa ${ }^{(5)}$. Ainda, eles relatam desestruturar-se, necessitando serem fortes para enfrentar o processo de hospitalização.

Perante a internação de uma criança em uma UTIP, as primeiras reações da criança dentro do processo, geram sentimentos negativos na família, dentre eles medo, tristeza, desespero, nervosismo, incertezas e a insegurança ${ }^{(14)}$. Sob essa ótica, o sentimento de tristeza se instala ao ver a criança em uma situação jamais vivida, sendo submetida a procedimentos e a um tratamento recém definido, impactando as famílias de tal modo que a incerteza e a insegurança se torna algo soberano que atinge a todos ${ }^{(5)}$. Além disso, a ansiedade é sentida pelos familiares ao participarem do sofrimento físico e emocional gerado pelo ambiente crítico, dificultando o processo de adaptação dos familiares durante a hospitalização ${ }^{(15)}$.

Concordando, destaca-se que a disfunção familiar pela internação de uma criança na UTIP pode ser intensificada por incertezas e anseios gerados pelas mudanças críticas e emergentes na saúde da criança. Assim, afirma-se que as fontes de estresse para os familiares incluem: insegurança relacionada ao ambiente da UTIP, a condição de saúde da criança e alterações causadas pela doença ${ }^{(13,16)}$ e até mesmo a proximidade com a morte.

O estímulo contextual está correlacionado com a ideia do familiar de que a UTIP relaciona-se com uma simbologia de morte, acrescida da percepção de um ambiente triste e desolador, a separação da criança. Surgem, então, reações que ressoarão diretamente no modo como ele lidará com tal situação. Nesse ambiente, o familiar se vê envolto em um contexto totalmente novo, em que o estresse, o temor e, em algumas vezes, a não aceitação diante da condição do filho são vivenciados constantemente ${ }^{(17)}$.

O ambiente de uma UTIP é repleto de equipamentos tecnológicos, o que pode desencadear tanto no acompanhante, quanto na criança o medo do desconhecido. Assim, o familiar pode apresentar um processo de adaptação com respostas ineficazes, dificultando o processo natural, prejudicando sua integralidade e o bem-estar familiar perante as circunstâncias impostas ${ }^{(3)}$.

Perante esse contexto, entende-se que "a hospitalização da criança na UTIP é altamente estressante, afeta todos os membros da família de várias formas"(18), elas sentem-se vulneráveis, sensíveis, a mercê do tratamento oferecido à criança, sem poder ajudar no processo. Assim, "as famílias, ao se depararem com o constrangedor mundo hospitalar: criam formas de enfrentamento, com vistas à cura e ao restabelecimento do doente e da dinâmica familiar"(18).

Estudo revela que os familiares sente-se sobrecaregados dentro da UTIP, com medo de ver seus filhos conectados a todos os aparatos, referindo a necessidade de familiarizar-se com a tecnologia pois confiam na ciência e acreditam que seus filhos estão sendo bem cuidados e vão melhorar ${ }^{(19)}$.

A vulnerabilidade humana se revela por meio do sofrimento e constitui uma realidade que acompanha a vida da família, em toda a sua trajetória, de modos e formas diferentes. Entende-se que, as famílias identificam sua sensibilidade profunda em seu sofrimento, em um mundo totalmente desconhecido, em que a equipe de saúde está à frente de todas as decisões que permeiam o processo.

Sob essa ótica, os familiares recebem estímulo contextual, que está presente no ambiente ${ }^{(3)}$, interligando o momento da internação e sua vulnerabilidade no processo como o pior momento de suas vidas. O momento constitui-se como algo que nunca tinham vivido, que traz sofrimento, associando o ambiente desconhecido com o medo do tratamento, da morte e das nuances que acompanham a internação na Unidade de Terapia Intensiva.

Nesse contexto, acredita-se que os familiares se sentem desestruturados, a mercê do diagnóstico a ser informado pela equipe de saúde, despidos de todo o controle que estavam acostumados. Eles relacionam, muitas vezes, sentimento de culpa e angústia pelo estado de saúde da criança, sendo impactados pelos dispositivos e sedativos, dentro do intenso tratamento ao paciente crítico.

Assim, ocorre que os familiares, em uma primeira visão, entendem a internação em uma UTIP como 'algo horrível', evoluindo, posteriormente, para o pensamento de que a criança está no melhor lugar que poderia estar, com o tratamento adequado para sua condição, passando de um comportamento de adaptação ineficaz para um de adaptação. "A família tenta adaptar-se efetivamente às mudanças geradas pela doença e pela hospitalização da criança, por encontrar significados positivos favorecedores do processo de enfrentamento e da adaptação às demandas adicionadas a sua vida diária”(20). Portanto, considerando os estímulos focal, contextual e as situações que confrontam os familiares durante a internação infantil, estes tendem a adaptar-se no decorrer da internação, sendo essa a melhor forma de enfrentamento, tornando-os mais fortes, e unidos.

Para atingir um nível de adaptação os familiares demonstram ter mecanismos de adaptação, gerando "sentimentos positivos, como a esperança da melhora no quadro de saúde da criança internada e a confiança de que no final tudo vai dar certo"(5). Assim, os familiares apontam o sentimento de esperança, ao verem que seu filho está no melhor local, com recursos e cuidados intensivos e com monitoramento 24 horas, como um mecanismo de adaptação.

As famílias revelam que seu sofrimento é amenizado durante a hospitalização da criança quando, por exemplo, acompanham a melhora do estado de saúde do seu filho e das outras crianças internadas na unidade; participam do cuidado e veem o empenho dos profissionais da saúde durante 
a internação ${ }^{(21)}$. Quando é permitido ao familiar cuidar da criança, reforça-se sua função do papel de cuidador principal, aquele que cuida do desenvolvimento do filho desde o princípio da vida, elevando, dessa forma, o modo de autoconceito, no que tange suas necessidades psicológicas, percebendo que ele é útil para o tratamento da criança ${ }^{(3)}$.

Nesse contexto, devido ao tratamento intensivo os familiares afirmam sentirem-se seguros e protegidos, com o olhar voltado para o tratamento completo que seus filhos irão receber e com esperança na melhora, a partir da definição do diagnóstico e do início do tratamento. Dessa forma, evidencia-se que apesar da gravidade do estado clínico da criança, o fato dela se encontrar em monitoramento 24 horas por uma equipe multidisciplinar treinada para o atendimento ao paciente crítico eleva o sentimento de segurança e proteção dos familiares, e em consequência diminui o sofrimento psíquico perante o impacto da internação infantil, revelando-se como um mecanismo de adaptação.

"O ser humano é um ser biopsicosociocultural-espiritual e qualquer alteração em uma destas dimensões ocasiona repercussões nas demais, o processo de doença e hospitalização é gerador de adaptações, mudanças e mobilização de conteúdos subjetivos"(22). Quando nos referimos a uma criança internada em UTIP, as emoções dos familiares podem ser mais intensas ${ }^{(22)}$, emergindo nesses familiares sentimentos negativos resultantes do impacto da internação. No entanto, com o passar do tempo eles demonstram tentativas de superação das adversidades, o que indica um padrão de adaptação às circunstâncias a serem enfrentadas.

Embora a UTI represente um ambiente desconhecido e estigmatizado, os familiares ao se depararem com a realidade do adoecimento e da hospitalização, com o passar dos dias, começam a reconhecê-lo e a adaptar-se a ele como um ambiente seguro em decorrência do suporte técnico e científico, que permite intervenções complexas e necessárias para recuperação da saúde da criança ${ }^{(22)}$. Aliado a busca da melhor forma de enfrentamento, os familiares nesta fase demonstram um nível de adaptação, com o pensamento positivo quanto a recuperação de seu filho, isso define-se como um ponto de mudança, que representa a capacidade da pessoa em responder positivamente em uma situação. Esse ponto de mudança é influenciado pelas exigências da situação e pelos recursos internos, incluindo capacidades, esperanças, sonhos, motivações e tudo o que faz a pessoa movimentar-se, constantemente, em direção ao domínio do processo de $\operatorname{adaptação(4).~}^{(4)}$.

Os mecanismos de adaptação são demonstrados também quando os familiares comparam o quadro clínico das demais crianças ao de seus filhos, sendo possível constatar uma evolução de cada criança, atrelando o pensamento positivo a cada dia vivido dentro da UTIP. Desse modo, os familiares vão adquirindo experiência e vencendo dia após dia de internação, desenvolvendo seus próprios mecanismos de adaptação, frente ao que consideram como 'a pior fase de suas vidas'.

Dessa forma, percebe-se que o desenvolvimento da adaptação é essencial para que os familiares consigam ter um enfrentamento adequado à internação de seus filhos na UTIP, independentemente de quais recursos utilizam para tal. A adaptação vai sendo desenvolvida pelos familiares com o passar dos dias, ao passo que a angústia e o sofrimento são minimizados, ao perceberem que seus filhos estão recebendo o melhor tratamento e o mais adequado para sua condição, despontando a esperança e o conforto.

Sobre toda a perspectiva apresentada, cabe a enfermagem realizar ações que reduzam a angústia, a sensação de medo, ansiedade e outros determinantes na criança e na família, sendo fundamental para que o atendimento aconteça de forma integral ${ }^{(23)}$. Deste modo, enfatiza-se a importância de realizar ações voltadas para escuta, afinidade, criação de vínculo, solidariedade, suporte de informações, sendo elas ferramentas que facilitarão o processo adaptativo eficaz dos familiares, ajudando-os a sentirem-se mais seguros diante da hospitalização infantil.

Nessa perspectiva, conhecer os mecanismos utilizados para a adaptação pode contribuir para que a enfermagem possa planejar uma assistência qualificada para a família e a criança hospitalizada, levando em conta todas suas particularidades referentes ao momento vivido e assim, consequentemente, realizar um cuidado holístico e integral e singular.

Torna-se importante salientar que o estudo apresentou limitações, evidencia-se o fato dele representar uma especifica realidade, devido a ter sido realizado em apenas um serviço de saúde. Diante disso, por possuir uma abordagem qualitativa não permite generalizações, mas sim o conhecimento da vivência do familiar para que seja possível elaborar estratégias específicas no enfrentamento da hospitalização da criança na UTIP pelos familiares, em prol de processos de adaptação mais eficazes.

\section{CONCLUSÃO}

O processo de adaptação vivenciado pela família frente à internação da criança na Unidade de Terapia Intensiva Pediátrica apresenta fases distintas. A partir do momento em que a família percebe a criança no leito da UTIP, em condição clínica grave, inicia-se o processo de adaptação e o aparecimento dos mecanismos que levam o familiar a uma adaptação eficaz.

Destaca-se como contribuição deste trabalho, a importância dos profissionais da saúde em conjunto com as famílias, durante o período de internação, construírem interações positivas, permitindo-lhes ser criativas e expressarem suas emoções. Além disso, deve-se atribuir significado a suas experiências, possibilitando que eles adquiram novos conhecimentos, promovendo, assim, a saúde familiar e da criança.

\section{RESUMO}

Objetivo: Conhecer o processo de adaptação de familiares ao vivenciar a internação da criança em uma Unidade de Terapia Intensiva. Método: Pesquisa qualitativa, descritiva e exploratória, realizada na Unidade de Pediatria, com familiares de crianças provenientes da Unidade de Terapia Intensiva Pediátrica. Utilizou-se a análise temática. Resultados: Participaram 13 familiares, 12 mães e um pai. Dos 
resultados emergiram as categorias: Impacto da família frente à internação infantil em Unidade de Terapia Intensiva Pediátrica e Mecanismos de adaptação de familiares à internação em uma Unidade de Terapia Intensiva Pediátrica. Conclusão: Os mecanismos adotados pela família no processo de adaptação da criança a internação na Unidade de Terapia Intensiva Pediátrica foram: pensamento positivo, entendimento do tratamento e de funcionamento da unidade. Os profissionais de saúde podem oferecer estratégias à família a fim de tornar a internação menos traumática, possibilitando o compartilhamento das experiências e a ampliação do conhecimento dos envolvidos.

\section{DESCRITORES}

Criança Hospitalizada; Família; Cuidadores; Unidade de Terapia Intensiva Pediátrica; Enfermagem Pediátrica; Relações Profissional-Família.

\section{RESUMEN}

Objetivo: Conocer el proceso de adaptación de familiares que vivencian el internamiento del niño en una Unidad de Terapia Intensiva. Método: Investigación cualitativa, descriptiva y exploratoria, realizada en la Unidad de Pediatría, con familiares de los niños provenientes de la Unidad de Terapia Intensiva Pediátrica. Utilizó se el análisis temático. Resultados: Participaron 13 familiares, 12 madres y 1 padre. De los resultados emergieran las categorías: Impacto de la familia frente al internamiento infantil en una Unidad de Terapia Intensiva Pediátrica y Mecanismos de adaptación de los familiares al internamiento en una Unidad de Terapia Intensiva Pediátrica. Conclusión: Los mecanismos adoptados por la familia en el proceso de adaptación del niño en la Unidad de Terapia Intensiva Pediátrica fueran: pensamiento positivo, entendimiento del tratamiento y del funcionamiento de la unidad. Los profesionales de la salud pueden ofrecer estrategias a la familia para tornar el internamiento menos traumático, posibilitando el compartiendo de las experiencias y la ampliación de lo conocimiento de los participantes envueltos.

\section{DESCRIPTORES}

Niño Hospitalizado; Familia; Cuidadores; Unidades de Cuidados Intensivos Pediátricos; Enfermería Pediátrica; Relaciones Profesional-Familia.

\section{REFERÊNCIAS}

1. Souza ABL, Beleza MCM, Andrade RFC. Novos arranjos familiares e os desafios ao Direito de família: uma leitura a partir do Tribunal de Justiça do Amazonas. Rev Eletr Hum Curso Ciênc Soc UNIFAP [Internet]. 2012 [citado 2018 jul. 28];(5):105-19. Disponível em: https:// periodicos.unifap.br/index.php/pracs/article/viewFile/577/n5Souza.pdf

2. Molina RCM, Higarshi IH, Marcon SS. Importância atribuída à rede de suporte social por mães com filhos em unidade intensiva. Esc Anna Nery. 2014;18(1):60-7. DOI: http://dx.doi.org/10.5935/1414-8145.20140009

3. Roy C, Andrews HA. The Roy adaptation model. $3^{\text {a }}$ ed. Stamford: Applet Lang; 2009

4. Neves L, Gondim AA, Soares SCMR, Coelho DP, Pinheiro JAM. The impact of the hospitalization process on the caregiver of a chronic critical patient hospitalized in a Semi-Intensive Care Unit. Esc Anna Nery. 2018;22(2):20170304. DOI: http://dx.doi.org/10.1590/21779465-EAN-2017-0304

5. Pêgo CO, Barros MMA. Unidade de Terapia Intensiva Pediátrica: expectativas e sentimentos dos pais da criança gravemente enferma. Rev Bras Ciênc Saúde. 2017;21(1):11-20. DOI: http://dx.doi.org/10.4034/RBCS.2017.21.01.02

6. Braun V. Clarke V. Using thematic analysis in psychology. Qual Res Psychol. 2006;3(2):77-101.

7. Brasil. Ministério da Saúde; Conselho Nacional de Saúde. Resolução n. 466 de 12 de dezembro de 2012. Dispõe sobre normas e diretrizes regulamentadoras de pesquisas envolvendo seres humanos [Internet] Brasília; 2012. [citado 2018 jul. 29]. Disponível em: http://bvsms. saude.gov.br/bvs/saudelegis/cns/2013/res0466_12_12_2012.html

8. Passos SSS, Silva JO, Santana VS, Santos VMN, Pereira A, Santos LM. O acolhimento no cuidado à família numa unidade de terapia intensiva. Rev Enferm UERJ. 2015;23(3):368-74. DOI: http://dx.doi.org/10.12957/reuerj.2015.6259

9. Beytut D, Özalp Gerçeker G, Karayağız Muslu G. A qualitative study exploring the needs of Turkish mothers in the Pediatric Intensive Care Unit. J Pediatr Res. 2018;5(4):187-93. DOI: https://doi.org/10.4274/jpr.37232

10. Nóia TC, Sant'Ana RSE, Santos ADS, Oliveira SC, Bastos Veras SMC, Lopes Júnior LC. Coping with the diagnosis and hospitalization of a child with childhood cancer. Invest Educ Enferm. 2015;33(3):465-72. DOI: https://dx.doi.org/10.17533/udea.iee.v33n3a10

11. Gedleh A, Lee S, Hill JA, Umukunda Y, Qaiser S, Kabiru J, et al. "Where Does it Come from?" Experiences among survivors and parents of children with retinoblastoma in Kenya. J Genet Couns. 2017;27(3):574-88. DOI: https://doi.org/10.1007/s10897-017-0174-8

12. Carlson EB, Spain DA, Muhtadie L, McDade-Montez L, Macia KS. Care and caring in the ICU: family members' distress and perceptions about staff skills, communication, and emotional support. J Crit Care. 2015;30(3):557-61. DOI: https://doi.org/10.1016/j.jcrc.2015.01.012

13. Hagstrom S. Family stress in pediatric critical care. J Pediatr Nurs. 2017;32:32-40. DOI: https://doi.org/10.1016/j.pedn.2016.10.007

14. Azevedo MSN, Oliveira ICS, Souza TV, Moraes JRMM, Martinez EA, Araújo BS. Empowerment of the mothers of children in a pediatric intensive care unit. Rev Bras Enferm [Internet]. 2018;71(3):998-1006. DOI: http://dx.doi.org/10.1590/0034-7167-2016-0689

15. Alvez MVMFF, Cordeiro JG, Luppi CHB; Nitsche Maria JT, Olbrich SRLR. Experience of family members as a result of children's hospitalization at the Intensive Care Unit. Invest Educ Enferm [Internet]. 2013 [cited 2018 July 29];31(2):191-200. Available from: http://www.scielo.org.co/scielo.php?script=sci_arttext\&pid=S0120-53072013000200004

16. Madrigal VN, Carroll KW, Faerber JA, Walter JK, Morrison WE, Feudtner C. Parental sources of support and guidance when making difficult decisions in the Pediatric Intensive Care Unit. J Pediatr. 2016;169:221-6. DOI: 10.1016/j.jpeds.2015.10.061

17. Rodrigues EN, Oliveira ERC, Julião AMS. Assistência em unidade de terapia intensiva pediátrica: percepção do acompanhante. Rev Interdisc [Internet]. 2014 [citado 2018 jul. 29];7 (4):39-49. Disponível em: https://revistainterdisciplinar.uninovafapi.edu.br/index.php/ revinter/article/viewFile/492/pdf_157

18. Motta MGC, Diefenbach GDF. Dimensões da vulnerabilidade para as famílias da criança com dor oncológica em ambiente hospitalar. Esc Anna Nery. 2013;17(3):482-90. DOI: http://dx.doi.org/10.1590/S1414-81452013000300011 
19. Sanabria MLV, Rodríguez LM. Needs of parents in caring for their children in a Pediatric Intensive Care Unit. Invest Educ Enferm. 2016;34(1):29-37. DOI: http://dx.doi.org/10.17533/udea.iee.v34n1a04

20. Salgado CL, Lamy ZC, Nina RVAH, Melo LA, Lamy F, Nina VS. A cirurgia cardíaca pediátrica sob o olhar dos pais: um estudo qualitativo. Rev Bras Cir Cardiovasc. 2011;26(1): 36-42. DOI: http://dx.doi.org/10.1590/S0102-76382011000100009

21. Souza FGM, Santos DMA, Lima HRFO, Silva DCM, Cabeça LPF, Perdigão ELL. O Familiar na Unidade de Terapia Intensiva Pediátrica: um contexto revelador de necessidades. Rev Pesq Cuid Fundam. 2015;7 Supl.:77-94. DOI: http://dx.doi.org/10.9789/2175-5361.2015.v7i5.77-94.

22. Gequelin J, Fernandes KF, Oliveira GP. Dyniewicz AN. Percepção de acompanhantes sobre a criança intubada em uti pediátrica. Cogitare Enferm. 2014;19(3):483-90.

23. Azevêdo AVS, Lançoni Júnior AC, Crepaldi MA. Nursing team, family and hospitalized child interaction: an integrative review. Ciênc Saúde Coletiva. 2017;22(11):3653-66. DOI: http://dx.doi.org/10.1590/1413- 812320172211.26362015 